\title{
GAMBARAN ERUPSI GIGI DESIDUI BERDASARKAN STATUS GIZI ANAK USIA 6-24 BULAN DI PUSKESMAS BAHU
}

\author{
${ }^{1}$ Chandra Sangande \\ ${ }^{2}$ Shirley E. S. Kawengian \\ ${ }^{3}$ Anindita P. S.
}

\author{
${ }^{1}$ Kandidat Skripsi Program Studi Kedokteran Gigi Fakultas Kedokteran \\ Universitas Sam Ratulangi Manado \\ ${ }^{2}$ Bagian Gizi Fakultas Kedokteran Universitas Sam Ratulangi Manado \\ ${ }^{3}$ Program Studi Kedokteran Gigi Fakultas Kedokteran Universitas Sam Ratulangi Manado \\ Email: chandrasangande@ymail.com
}

\begin{abstract}
Nutritional status is the health status generated by a balance between the needs and input of nutrients. Children aged 6-24 months have a period of growth and development of deciduous teeth that is very important. Delayed deciduous tooth eruption in children is one impact of malnutrition. This study aimed to reveal deciduous tooth eruptions based on the nutritional status of children aged 6-24 months in Bahu Health Center. This was a descriptive study. Samples were obtained by using a purposive sampling method. Examinations of teeth eruptions were carried out by looking at deciduous teeth that had erupted. Nutritional status was assessed using the indicator of weight for age (W/A). Data of age were calculated using the z-score. Concerning their nutritional status, the results showed that $0.86 \%$ of the samples were overweight; $82.60 \%$ were well-nourished; $13.04 \%$ were less-nourished; and $3.47 \%$ suffered from malnutrition. Furthermore, related to their nutritional status, the percentages of the children who experienced complete deciduous teeth eruption were as follow: $100 \%$ in overweight, $21.05 \%$ in well-nourished, $40.00 \%$ in less-nourished, and $0.00 \%$ in malnutrition. Conclusion: Most of the children aged 6-24 months in Bahu Health Center were wellnourished. Complete deciduous teeth eruption were found in a single overweight child, a part of well-nourished and less-nourished children, and none in malnutrition children.
\end{abstract}

Keywords: deciduous teeth, tooth eruption, nutritional status.

\begin{abstract}
Abstrak: Status gizi ialah status kesehatan yang dihasilkan oleh keseimbangan antara kebutuhan dan asupan nutrisi. Anak berusia 6-24 bulan memiliki masa pertumbuhan dan perkembangan gigi desidui yang sangat penting untuk diperhatikan. Keterlambatan erupsi gigi desidui pada anak merupakan salah satu akibat kekurangan gizi. Penelitian ini bertujuan untuk mengetahui gambaran erupsi gigi desidui berdasarkan status gizi anak usia 6-24 bulan di Puskesmas Bahu. Penelitian ini bersifat deskriptif. Pemilihan sampel dilakukan dengan cara purposive sampling. Pemeriksaan erupsi gigi dilakukan dengan melihat gigi desidui yang telah erupsi. Status gizi dinilai dengan indikator berat badan menurut usia $(\mathrm{BB} / \mathrm{U})$, pengambilan data usia, kemudian dihitung dalam nilai z-skor. Hasil penelitian menunjukkan subyek dengan status gizi lebih $0,86 \%$; status gizi baik $82,60 \%$; status gizi kurang $13,04 \%$; dan status gizi buruk $3,47 \%$. Erupsi gigi desidui lengkap ditemukan pada subyek dengan status gizi lebih 100,00\%; status gizi baik 21,05\%; status gizi kurang 40\%; dan status gizi buruk 0,00\%. Simpulan: Sebagian besar anak berusia 6-24 bulan di Puskesmas Bahu memiliki status gizi baik. Erupsi gigi desidui lengkap ditemukan pada anak dengan status gizi lebih serta sebagian anak dengan status gizi baik dan kurang, tetapi tidak ditemukan pada anak dengan status gizi buruk.
\end{abstract}

Kata kunci: gigi desidui, erupsi gigi, status gizi. 
Masalah gizi merupakan salah satu masalah yang dihadapi negara-negara berkembang, termasuk Indonesia. Baik media masa maupun hasil survei melaporkan masih banyak daerah di Indonesia dengan masyarakat yang mengalami kurang gizi atau gizi buruk, terutama balita. Hasil analisis data antropometri Direktorat Bina Gizi Masyarakat dari tahun 1989 sampai dengan tahun 2003 menunjukan gizi buruk pada balita sangat meningkat. Hasil data status gizi balita yang diperoleh Riset Kesehatan Dasar menunjukan pada tahun 2010 prevalensi berat badan kurang 17,9\%, yang terdiri dari $4,9 \%$ gizi buruk dan $13,0 \%$ gizi kurang. ${ }^{1}$

Balita termasuk dalam golongan masyarakat rentan gizi karena sedang mengalami proses pertumbuhan relatif cepat. Defisiensi zat gizi pada balita dapat menyebabkan terganggunya kesehatan dan pertumbuhan, serta terhambatnya erupsi gigi. Keterlambatan erupsi gigi juga dapat terjadi karena adanya variasi waktu erupsi normal gigi. ${ }^{2,3}$

\section{METODE PENELITIAN}

Penelitian ini merupakan penelitian deskriptif yang dilakukan di Posyandu Puskesmas Bahu. Sampel diambil dengan menggunakan teknik purposive sampling Jumlah sampel berjumlah 115 anak berdasarkan perhitungan Slovin.

Pengumpulan data diperoleh melalui studi lapangan dan pemeriksaan klinis. Anak yang datang ditimbang berat badannya dengan menggunakan alat timbang berat badan One Med Baby Scale $20 \mathrm{~kg}$, kemudian dilihat gigi desidui yang sudah tumbuh. Anak yang telah datang dan ditimbang di Posyandu Puskesmas Bahu tidak akan diperiksa kembali bila anak tersebut datang kembali di Posyandu Puskesmas Bahu selama penelitian dilakukan.

Penilaian hasil pemeriksaan status gizi (berat badan per usia) anak dinilai dengan menggunakan standar WHO (z-skor) dengan kategori derajat status gizi sebagai berikut: kategori gizi lebih dengan z-skor $>2,0$; gizi baik dengan $\mathrm{z}$-skor >-2,0 sampai dengan 2; gizi kurang dengan z-skor >-3,0 sampai dengan $<-2,0$; dan gizi buruk $\mathrm{z}$-skor $<-3,0 .{ }^{2}$ Penilaian hasil pemeriksaan erupsi gigi dilakukan dengan melihat keadaan gigi yang keluar dari gusi ditandai oleh munculnya mahkota gigi berwarna putih yang keluar dari gusi. Tabel 1 memperlihatkan erupsi gigi desidui berdasarkan usia, dan dipergunakan untuk menilai kelengkapan gigi desidui.

Tabel 1. Erupsi gigi desidui bersarkan usia. ${ }^{3}$

\begin{tabular}{lc}
\hline Gigi & Erupsi (bulan) \\
\hline Insisivus perama & $5-7$ \\
Insisivus kedua & $7-8$ \\
Kaninus & $16-20$ \\
Molar pertama & $12-16$ \\
Molar kedua & $20-30$ \\
\hline
\end{tabular}

\section{HASIL PENELITIAN}

Penelitian dilakukan di Puskesmas Bahu pada anak berusia 6-24 bulan. Jumlah sampel yang diperiksa yaitu 115 anak, terdiri dari 70 laki-laki $(60,86 \%)$ dan 45 perempuan $(39,13 \%)$ (Tabel 2).

Tabel 2 menunjukkan bahwa sebagian besar subjek memiliki gizi baik $(82,60 \%)$, diikuti gizi kurang $(13,04 \%)$, gizi buruk $(3,47 \%)$, dan gizi lebih $(0,86 \%)$.

Tabel 2. Status gizi menurut jenis kelamin.

\begin{tabular}{lllllll}
\hline \multirow{2}{*}{$\begin{array}{c}\text { Status } \\
\text { gizi }\end{array}$} & \multicolumn{6}{c}{ Jenis kelamin } \\
\multicolumn{1}{c}{ Laki-laki Perempuan } & \multirow{2}{*}{ Total (\%) } \\
\cline { 2 - 5 } & $\mathbf{n}$ & $\mathbf{( \% )}$ & $\mathbf{n}$ & $\mathbf{( \% )}$ & & \\
\hline Gizi lebih & 1 & $(0,86)$ & 0 & $(0,00)$ & 1 & $(0,86)$ \\
Gizi baik & 59 & $(51,30)$ & 36 & $(31,30)$ & 95 & $(82,60)$ \\
$\begin{array}{l}\text { Gizi } \\
\text { kurang }\end{array}$ & 8 & $(6,95)$ & 7 & $(6,08)$ & 15 & $(13,04)$ \\
$\begin{array}{l}\text { Gizi } \\
\text { buruk }\end{array}$ & 2 & $(1,73)$ & 2 & $(1,73)$ & 4 & $(3,47)$ \\
Total & 70 & $(60,86)$ & 45 & $(39,13)$ & 115 & $(100,00)$ \\
\hline
\end{tabular}

Tabel 3 menunjukkan bahwa status gizi lebih hanya ditemukan pada 1 anak $(100,00 \%)$ dengan erupsi desidui gigi i1 
dan i2 lengkap sesuai usia dentalis. Pada status gizi baik terdapat 20 anak $(21,05 \%)$ yang telah erupsi desidui lengkap dan 75 anak $(78,94 \%)$ tidak erupsi lengkap (Tabel 4). Pada status gizi kurang terdapat 6 anak $(40,00 \%)$ yang erupsi lengkap dan 9 anak $(60,00 \%)$ tidak erupsi lengkap. Tabel 5 menunjukkan bahwa pada gizi buruk tidak terdapat anak dengan erupsi gigi desidui lengkap.

Tabel 3. Erupsi gigi desidui pada gizi lebih.

\begin{tabular}{lcccc}
\hline \multirow{2}{*}{ Usia (gigi) } & \multicolumn{2}{c}{ Status gizi lebih } & & \\
\cline { 2 - 4 } & $\begin{array}{c}\text { Lengkap } \\
(\%)\end{array}$ & $\begin{array}{c}\text { Tidak } \\
\text { lengkap (\%) }\end{array}$ & n & \\
\hline $6-12(\mathrm{i} 1, \mathrm{i} 2)$ & $1(100,00)$ & $0(0,00)$ & 1 & 100,00 \\
$12-16(\mathrm{~m} 1)$ & $0(0,00)$ & $0(0,00)$ & 0 & 0,00 \\
$16-20(\mathrm{c})$ & $0(0,00)$ & $0(0,00)$ & 0 & 0,00 \\
$20-30(\mathrm{~m} 2)$ & $0(0,00)$ & $0(0,00)$ & 0 & 0,00 \\
Total & $1(100,00)$ & $0(0,00)$ & 1 & 100,00 \\
\hline
\end{tabular}

Tabel 4. Erupsi gigi desidui pada gizi baik.

\begin{tabular}{lcccc}
\hline \multirow{2}{*}{ Usia (gigi) } & \multicolumn{2}{c}{ Status gizi baik } & & \\
\cline { 2 - 3 } & $\begin{array}{c}\text { Lengkap } \\
(\boldsymbol{\%})\end{array}$ & $\begin{array}{c}\text { Tidak } \\
\text { lengkap (\%) }\end{array}$ & & \multirow{\%}{*}{} \\
\hline $6-12(\mathrm{i} 1, \mathrm{i} 2)$ & $7(7,36)$ & $57(60,00)$ & 64 & 67,36 \\
$12-16(\mathrm{~m} 1)$ & $6(6,31)$ & $3(3,15)$ & 9 & 9,47 \\
$16-20(\mathrm{c})$ & $3(3,15)$ & $7(7,36)$ & 10 & 10,52 \\
$20-30(\mathrm{~m} 2)$ & $4(4,21)$ & $8(8,42)$ & 12 & 12,63 \\
Total & $20(21,05)$ & $75(78,94)$ & 95 & 100,00 \\
\hline
\end{tabular}

Tabel 5. Erupsi gigi desidui pada gizi buruk.

\begin{tabular}{lcccc}
\hline $\begin{array}{l}\text { Usia } \\
\text { (gigi) }\end{array}$ & \multicolumn{2}{l}{ Status gizi buruk } & & \multicolumn{2}{c}{$\begin{array}{l}\text { Lengkap } \\
(\%)\end{array}$} & $\begin{array}{l}\text { Tidak } \\
\text { lengkap (\%) }\end{array}$ & & \\
\hline $6-12(\mathrm{i} 1, \mathrm{i} 2)$ & $0(0,00)$ & $3(50,00)$ & 3 & 75,00 \\
$12-16(\mathrm{~m} 1)$ & $0(0,00)$ & $0(0,00)$ & 0 & 0,00 \\
$16-20(\mathrm{c})$ & $0(0,00)$ & $0(0,00)$ & 0 & 0,00 \\
$20-30(\mathrm{~m} 1)$ & $0(0,00)$ & $1(50,00)$ & 1 & 25,00 \\
Total & $0(0,00)$ & $4(100,00)$ & 4 & 100,00 \\
\hline
\end{tabular}

\section{BAHASAN}

Sampel pada penelitian ini ialah 115 anak berusia 6-24 bulan. Hasil penelitian menunjukkan bahwa hanya 1 anak $(100,00 \%)$ dengan status gizi lebih dan erupsi gigi desidui lengkap (Tabel 3). Hal ini serupa dengan penelitian SanchezPerez, et al. ${ }^{4}$ pada 110 anak di Meksiko (2010) yang menemukan bahwa anak dengan status gizi lebih memiliki gigi yang telah erupsi lebih banyak dibandingkan anak dengan status gizi yang lebih rendah. Hal ini didukung oleh penelitian Hilgerz et al. ${ }^{5}$ di Amerika Serikat (2006) yang menunjukkan bahwa pada anak dengan berat badan lebih terjadi percepatan pertumbuhan gigi. Suplementasi yang tinggi pada ibu hamil merupakan salah satu faktor penyebab erupsi gigi lebih cepat. Penelitian Delgado et al. ${ }^{3}$ di Amerika Serikat (1975) menyatakan bahwa anak yang lahir dari ibu dengan suplementasi tinggi (>20.000 kkl) ketika hamil akan mengalami percepatan erupsi gigi dibandingkan yang lahir dari ibu dengan suplementasi kurang $(<10.000 \mathrm{kkl})$.

Hasil penelitian pada status gizi baik menunjukkan bahwa terdapat 20 anak $(21,05 \%)$ dengan erupsi gigi lengkap, dan 75 anak $(78,94 \%)$ dengan erupsi gigi tidak lengkap (Tabel 4). Hal yang serupa juga ditemukan pada berbagai penelitian sebelumnya. Penelitian Falkner ${ }^{6}$ pada anak Guetemalan Ladino (1957), McGregor $^{7}$ pada anak Gambia (1968), dan Bailey pada anak New Guinea (1964), ${ }^{8}$ juga menunjukkan adanya erupsi gigi yang tidak lengkap pada anak dengan status gizi yang baik, tanpa mencantumkan jumlah gigi erupsi yang lengkap dan tidak lengkap sehingga tidak dapat dilakukan pembandingan hasil yang diperoleh. Para peneliti juga tidak menjelaskan penyebab terjadinya erupsi yang tidak lengkap pada anak dengan status gizi baik. Faktor-faktor lain yang dapat mengakibatkan keterlambatan erupsi gigi desidui ialah: berat badan lahir rendah, suku (ras), trauma, dan ankilosis. ${ }^{6-8}$

Hasil penelitian menunjukkan bahwa pada status gizi kurang terdapat 6 anak $(40,00 \%)$ dengan erupsi gigi yang lengkap. Hasil penelitian ini serupa dengan penelitian Gaur dan Kumar pada 510 anak di India pada tahun 2012 yang menunjukan 
bahwa pada anak kurang gizi akan terjadi penurunan berat badan serta keterlambatan erupsi gigi desidui. Studi lain yang dilakukan oleh Delgado et al. ${ }^{4}$ (1975) pada anak Guetemala Ladino dan Rami (1981) pada anak Gulbarga India menunjukkan bahwa pengaruh gizi kurang terhadap erupsi gigi desidui sangat sedikit bahkan tidak ada pengaruh antara waktu erupsi gigi desidui dengan status malnutrisi seorang anak. Faktor genetik juga berperan sebagai penyebab variasi erupsi gigi. ${ }^{9,10}$

Hasil penelitian menunjukkan bahwa semua anak (100,00\%) dengan gizi buruk memperlihatkan erupsi gigi tidak lengkap (Tabel 5). Hasil ini sesuai dengan penelitian yang dilakukan Alvarez et al. (1988, 1990, dan 1995) di Peru, ${ }^{10-12}$ Barrett dan Brown ${ }^{13}$ (1966) pada anak Aborigin, el Lozy et al. ${ }^{14}$ (1975) pada anak Tunisia, serta Enwonwu ${ }^{15}$ (1973) pada anak Nigeria yang menunjukkan bahwa pada anak dengan status gizi malnutrisi terjadi keterlambatan erupsi gigi. Selain itu, penelitian Psoter et al. ${ }^{16}$ pada 498 anak di Haiti (2008) menunjukkan bahwa terjadinya keterlambatan erupsi gigi desidui dapat disebabkan oleh malnutrisi.

\section{SIMPULAN}

Dari hasil penelitian dapat disimpulkan bahwa sebagian besar anak berusia 6-24 bulan di Puskesmas Bahu memiliki status gizi baik. Erupsi gigi desidui lengkap ditemukan pada anak dengan status gizi lebih serta sebagian kecil anak dengan status gizi baik dan kurang, tetapi tidak ditemukan pada anak dengan status gizi buruk.

\section{SARAN}

Dapat dilakukan penelitian mengenai berat badan lahir, keadaan sistemik, dan genetik untuk mengetahui faktor-faktor yang menyebabkan keterlambatan erupsi gigi desidui.

\section{DAFTAR PUSTAKA}

1. Status gizi balita [homepage on the Interenet]. 2011 [cited 2012 Des 02] Available from: URL: http://dietitian side.blogspot.com

2. Supariasa IDN, Bakri B, Fajar I. Penilaian Status Gizi. Jakarta: EGC, 2002; p.71.

3. Delgado H, Habicht JP, Yarbrough, Lechtig A, Martorell, Malina RM, Klein RE. Nutritional status and the timing of deciduous tooth eruption. Am J Clin Nutr. 1975;28(3):216-24.

4. Sánchez-Póez L, Irigoyen ME, Zepeda M. Dental caries, tooth eruption timing and obesity: a longitudinal study in a group of Mexican schoolchildren. Acta Odontol Scand. 2010;68(1):57-64.

5. Hilgers KK, Akridge M, Scheetz JP, Kinane DE. Childhood obesity and dental development. Pediatr Dent. 2006;28(1):18-22.

6. Falkner F. Deciduous tooth eruption. Arch Dis Child. 1957;32(165):386-91.

7. McGregor IA, Thomson AM, Billewicz WZ. The development of primary teeth in children from a group of Gambian villages, and critical examination of its use for estimating age. $\mathrm{Br} \mathrm{J}$ Nutr. 1968;22(2):307-14.

8. Peedikayil FC. Delayed tooth eruption. ejournal of Dentistry. 2011;1:81-6.

9. Gaur R, Kumar P. Effect of undernutrition on deciduous tooth emergence among raj put children of shimla district of hemachal pradesh india. Am J Phys Antrhopol. 2012;148(1):54-61.

10. Alvarez JO, Lewis CA, Saman C, Caceda J, Montalvo J, Figueroa ML, et al. Chronic malnutrition, dental caries, and tooth exfoliation in Peruvian children aged 3- 9 years. Am J Clin Nutr. 1988;48(2):368-72.

11. Alvarez JO, Caceda J, Woolley TW, Carley KW, Baiocchi N, Caravedo L, et al. A longitudinal study of dental caries in the primary teeth of children who suffered from infant malnutrition. J Dent Res. 1993;72(12):1573-6.

12. Alvarez JO. Nutrition, tooth development, and denta caries. Am J Clin Nutr. 1995;61:410S-416S.

13. Barrett MJ, Brown T. Eruption of deciduous teeth in Australian aborigines. Aust Dent J. 1966;11(1):43-50. 
14. el Lozy M, Reed RB, Kerr GR, Boutourline E, Tesi G, Ghamry MT, Stare FJ, et al. Nutritional correlates of child development in southern Tunisia. IV. The relation of deciduous dental eruption to somatic development. Growth. 1975;39(2):209-21.

15. Enwonwu CO. Influence of socio- economic conditions on dental development in Nigerian children. Arch Oral Biol. 1973;18(1):95-107.

16. Psoter W, Gebrian B, Pohete S, Reid B, Katz R. Effect of early childhood malnutrition on tooth eruption in Haitian adolescents. Community Dent Oral Epidemiol. 2008;36(2):179-89. 